\title{
17-Year-Old Runner with Shin Pain
}

\author{
Lesley Flynt and Helena R. Balon \\ Department of Radiology and Molecular Imaging, Oakland University William Beaumont School of Medicine and Beaumont \\ Health System, Royal Oak, Michigan
}

Stress injury is a common cause of exercise-induced anterior shin pain. It is important to distinguish between the various causes of stress injury in a timely manner in order to optimize favorable treatment outcomes. Here, we will discuss a case of medial tibial stress syndrome, or shin splints, as one of the causes of shin pain, as well as how to approach shin pain for a successful diagnosis.

Key Words: bone; joint/muscle; molecular imaging; pediatrics; bone scan; medial tibial stress syndrome

J Nucl Med Technol 2014; 42:238-239

DOI: 10.2967/jnmt.113.135897

$\mathbf{T}$ his case study demonstrates the ability of bone scintigraphy to diagnose stress injury when radiography findings are negative and to differentiate between medial tibial stress syndrome and stress fracture. The typical scintigraphic patterns of both entities are discussed.

\section{CASE REPORT}

A 17-y-old female runner presented with shin pain, greater in the right shin than in the left. No radiographic images were available for review at the time of patient presentation.

Immediately after the intravenous administration of 851 $\mathrm{MBq}(23 \mathrm{mCi})$ of ${ }^{99} \mathrm{~m} \mathrm{Tc}-m e t h y l e n e$ diphosphonate, flow and blood pool images of the lower legs were obtained. Delayed static anterior, posterior, and lateral views of the tibiae and fibulae and of the feet were also obtained.

Flow and blood pool images of the lower extremities (Figs. $1 \mathrm{~A}$ and $1 \mathrm{~B})$ revealed no abnormalities. Delayed imaging (Figs. 1C and 1D) demonstrated mild segmental linearly increased uptake along the posterior medial cortex of the distal third of the right tibia as well as minimal scattered multifocal increased uptake along the medial cortex of the left tibia in several segments. These findings were consistent with medial tibial stress syndrome (also known as shin splints), better defined in the right leg and probably very early in the left leg.

Received Nov. 29, 2013; revision accepted Feb. 5, 2014.

For correspondence or reprints contact: Lesley Flynt, Oakland University William Beaumont School of Medicine and Beaumont Health System, 3601 W.

13 Mile Rd., Royal Oak, Ml 48073.

E-mail: lesley.flynt@beaumont.edu

Published online Jun. 26, 2014.

COPYRIGHT (C 2014 by the Society of Nuclear Medicine and Molecular Imaging, Inc.

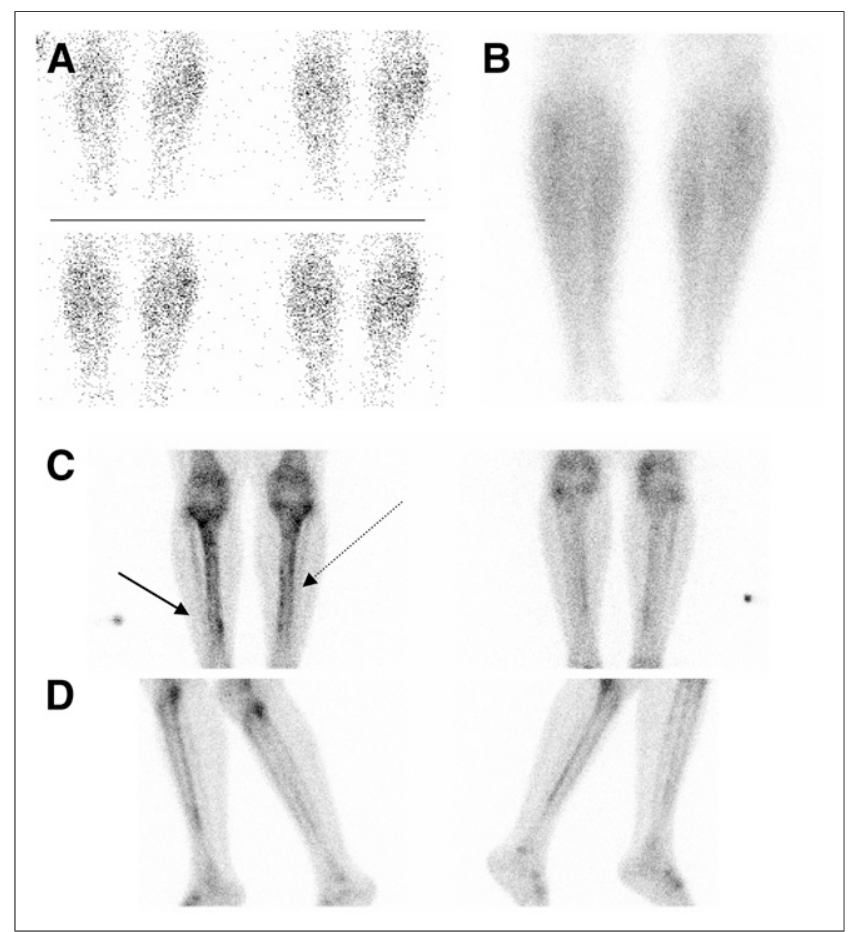

FIGURE 1. (A and B) Anterior blood flow (A) and blood pool (B) images demonstrate symmetric distribution of radiotracer. ( $C$ and D) Anterior (left) and posterior (right) views (C) and right medial and left lateral (left) and left medial and right lateral (right) views (D) of lower extremities demonstrate linear multifocal increased uptake along posteromedial cortex of distal right tibia (solid arrow) and minimal scattered foci along medial cortex of left tibia (dotted arrow). 
the posteromedial tibial cortex. This increased stress leads to increased tension and pulling of the muscle on the periosteum of the tibia, resulting in stress along the diaphysis $(1,2)$. The linear pattern (on the delayed phase of the bone scan only) thus represents periostitis along the insertion of these muscles (3).

In contrast, a stress fracture has increased perfusion and blood pool activity on 3-phase bone scanning. On the delayed phase, it appears as a fusiform focus of intense increased radiotracer uptake of varying thickness, depending on the grade (3). The tibia is the most common site of stress fracture in athletes.

Plain radiographs are often the first line of investigation; however, fractures will not begin to appear on radiographs until 7-10 d after the initial insult. Radiography has low sensitivity for stress fractures, and the findings are always negative for patients with shin splints (4).

Medial tibial stress syndrome is often diagnosed by clinical presentation alone. Depending on the severity and location, stress fractures may be treated with rest; ice; elevation; slow, non-weight-bearing, rehabilitative exercises; immobilization with a cast or splint; or, in more severe cases, surgery. Patients with shin splints often resume physical activity gradually, as tolerated, usually within $1 \mathrm{wk}$ but sometimes in as long as $3 \mathrm{mo}$. The time until patients with stress fractures resume physical activity is relative but is usually approximately 3 mo for low-intensity activity and up to 6 mo for full intensity (4).

\section{CONCLUSION}

While standard radiographs are generally the first tool used in the path to diagnosis of anterior shin pain, bone scintigraphy may prove more useful when differentiating between shin splints and stress fracture, or if the patient presents for imaging less than 10 days after the initial injury, which is usually the case.

\section{DISCLOSURE}

No potential conflict of interest relevant to this article was reported.

\section{REFERENCES}

1. Moen MH, Tol JL, Weir A, Steunebrink M, De Winter TC. Medial tibial stress syndrome: a critical review. Sports Med. 2009;39:523-546.

2. Reshef N, Guelich DR. Medial tibial stress syndrome. Clin Sports Med. 2012;31:273-290.

3. Love C, Din AS, Tomas MB, Kalapparambath TP, Palestro CJ. Radionuclide bone imaging: an illustrative review. Radiographics. 2003;23:341-358.

4. Heaslet MW, Kanda-Mehtani SL. Return-to-activity levels in 96 athletes with stress fractures of the foot, ankle, and leg: a retrospective analysis. J Am Podiatr Med Assoc. 2007;97:81-84. 